Article

\title{
Selenium Deficiency in Lymphedema and Lipedema-A Retrospective Cross-Sectional Study from a Specialized Clinic
}

\author{
Christina Pfister ${ }^{1, *}$, Horst Dawczynski ${ }^{1}$ and Franz-Josef Schingale ${ }^{2}$ \\ 1 Biosyn Arzneimittel GmbH, Schorndorfer Straße 32, 70734 Fellbach, Germany; horst_dawczynski@biosyn.de \\ 2 Lympho Opt Fachklinik, Happurger Straße 15, 91224 Hohenstadt, Germany; \\ franz-josef.schingale@lympho-opt.de \\ * Correspondence: chpfister@t-online.de; Tel.: +49-711-57532-321
}

Received: 26 March 2020; Accepted: 24 April 2020; Published: 25 April 2020

\begin{abstract}
Background: Selenium is a trace element, which is utilized by the human body in selenoproteins. Their main function is to reduce oxidative stress, which plays an important role in lymphedema and lipedema. In addition, selenium deficiency is associated with an impaired immune function. The aim of this study was to determine the prevalence of selenium deficiency in these conditions, and if it is associated with disease severity and an associated medical condition such as obesity. Methods: This cross-sectional study is an anonymized, retrospective analysis of clinical data that was routinely recorded in a clinic specialized in lymphology. The data was comprised from 791 patients during 2012-2019, in which the selenium status was determined as part of their treatment. Results: Selenium deficiency proved common in patients with lymphedema, lipedema, and lipo-lymphedema affecting $47.5 \%$ of the study population. Selenium levels were significantly lower in patients with obesity-related lymphedema compared to patients with cancer-related lymphedema $(96.6 \pm 18.0 \mu \mathrm{g} / \mathrm{L}$ vs. $105.1 \pm 20.2 \mu \mathrm{g} / \mathrm{L} ; p<0.0001)$. Obesity was a risk factor for selenium deficiency in lymphedema (OR 2.19; 95\% CI 1.49 to 3.21), but not in lipedema. Conclusions: In countries with low selenium supply, selenium deficiency is common, especially in lymphedema patients. Therefore, it would be sensible to check the selenium status in lymphedema patients, especially those with obesity, as the infection risk of lymphedema is already increased.
\end{abstract}

Keywords: selenium; lymphedema; lipedema; obesity; oxidative stress; inflammation

\section{Introduction}

Clinics specialized in lymphological diseases manage not only patients with cancer treatmentrelated secondary lymphedema, but also treat patients with primary lymphedema, as well as secondary lymphedema due to obesity, lipedema, or lipo-lymphedema. The pathogenesis of lymphedema is a progressive process, consisting of lymphatic leakage and stagnation, chronic inflammation, adipose tissue expansion and fibrosis [1]. In contrast to lymphedema, lipedema is characterized by bilaterally increased circumference of extremities, pain sensation, and bruising [2]. Lipedema leaves most distal parts of the body, i.e., hands and feet, unaffected. In early stages, lipedema shows increased lymphatic flow, not lymphatic insufficiency [3]. The tissue water content in lipedema patients is in the range of healthy controls [4]. However, patients with lipedema may develop secondary lymphedema, if the fatty deposits compromise the lymphatic system [5]. The combination of lipedema and lymphatic impairment is called lipo-lymphedema [6].

Secondary lymphedema is mostly associated with cancer treatment as common and debilitating progressive sequelae. Recently, another reason has come to the fore: obesity-related lymphatic 
impairment [7]. Obesity is usually defined as a body mass index (BMI) $\geq 30 \mathrm{~kg} / \mathrm{m}^{2}$. In lipedema, obesity is proving to be the most common comorbidity. Up to $80 \%$ of lipedema patients are obese [8]. Obese patients with lipedema are at risk for obesity-associated lymphedema [2].

Obesity appears to be associated with selenium deficiency [9-11]. A reduced selenium status is significantly associated with a BMI $\geq 30 \mathrm{~kg} / \mathrm{m}^{2}$ in women [10,11]. Alasfar et al. showed that morbidly obese patients (BMI $\geq 40 \mathrm{~kg} / \mathrm{m}^{2}$ ) display significantly reduced serum selenium concentrations [12]. Significantly reduced selenium status in obesity appears to result from obesity-related oxidative stress [13]. Obesity is moreover associated with a state of chronic inflammation, which also contributes to the pro-oxidant environment of the condition [14].

Selenium plays an important role in inflammation and immunity [15]. Selenium deficiency negatively affects immune cells during activation, differentiation, and proliferation. This is related to increased oxidative stress. Functions like protein folding and calcium flux in immune cells may also be impaired under selenium deficient conditions [15]. Erysipelas are frequent infectious complications of lymphedema [16]. Kasseroller et al. showed that high-dose sodium selenite-an inorganic selenium form-can reduce the incidence of erysipelas [17]. Selenium status was not determined in this study or in other comparable trials [18-20]. Therefore, it is an open question; if selenium deficiency may be problematic, sufficiency could be protective or lymphedema treatment with high-dosed sodium selenite could be independent of selenium status.

In obesity, lymphatic function in adipose tissue and drainage capacity in the lower extremities seems to be reduced [21]. In the tissue of chronic lymphedema patients, the formation of reactive oxygen species (ROS) is enhanced and lipid peroxidation processes are accelerated [22]. Siems et al. additionally showed that reduced glutathione (GSH) concentrations in blood were decreased in chronic lymphedema patients and glutathione disulfide (oxidized glutathione; GSSG) was elevated, resulting in a three-fold higher glutathione ratio, an indicator for oxidative stress [22]. The authors concluded that the oxidative stress related changes are a consequence of the lymphedema, since the control group that had treated tumors but no lymphedema had data comparable to the healthy controls. In lipedema patients, Siems et al. showed that serum concentrations of malondialdehyde (MDA) and plasma protein carbonyls were increased compared to healthy controls [23]. Therefore, oxidative stress also plays an important role in lipedema.

The functional gene expression analysis of a mouse model of acute acquired lymphedema showed that genes involved in the immune response, stress response, and complement activation were induced in lymphedema tissue [24]. These included several, mostly stress-responsive, selenoproteins, i.e., glutathione peroxidase 1 . These selenoproteins are highly dependent on an adequate selenium supply. Glutathione peroxidase 1 reaches maximal activity at plasma selenium concentrations of $95 \mu \mathrm{g} / \mathrm{L}$ [25]. In selenium deficiency, glutathione peroxidase 1 is depleted in many organs [26]. The selenium transport protein, selenoprotein $\mathrm{P}$, does not reach optimal activity in the plasma until $124 \mu \mathrm{g} / \mathrm{L}$ selenium [27]. Mean serum selenium levels in Germany are much lower than in other countries, with values of 74.3 (95\% CI 69.8-79.0) $\mu \mathrm{g} / \mathrm{L}$ registered in men and 73.2 (95\% CI 67.4-79.6) $\mu \mathrm{g} / \mathrm{L}$ in women [28]. Muecke et al. determined whole blood selenium concentrations in healthy males. Mean selenium value was $74.1 \pm 23.0 \mu \mathrm{g} / \mathrm{L}$. The selenium range was 43.6 to $127.0 \mu \mathrm{g} / \mathrm{L}$ [29], probably due to low selenium intake (34-60 $\mu \mathrm{g}$ selenium per day) [30]. The reference values for selenium intake in Germany for adults are $70 \mu \mathrm{g}$ for men and $60 \mu \mathrm{g}$ for women [31].

The aim of this observational study was to determine the prevalence of selenium deficiency in patients with primary or secondary lymphedema, lipedema, or lipo-lymphedema. In addition, the influence of obesity on the selenium status in these patients was evaluated. 


\section{Materials and Methods}

\subsection{Study Design}

An ethics committee vote was not necessary, because clinic intern register data were used in this retrospective cross-sectional study. The data was raised routinely in patient care. Written informed consents for the data analysis of patient data were obtained from all participating patients in accordance with the Declaration of Helsinki. The clinical data were recorded in a clinic specialized in lymphology (Lympho-Opt Clinic Pommelsbrunn-Hohenstadt, Germany). The data of patients treated for lymphedema, lipedema or lipo-lymphedema, in which the selenium status was determined as part of their treatment, were anonymized for two time periods: from 2012 to $2016(n=236)$ and from 2018 to $2019(n=555)$. The anonymized data included gender, diagnosis, BMI, and selenium concentrations in whole blood. Diagnosis was determined by FJS based on the German S2K guidelines, which included positive Stemmer's test, sonography or indocyanine green (ICG) fluorescence lymphography [32]. Overweight and obesity were classified according to BMI (overweight 25 to $29.9 \mathrm{~kg} / \mathrm{m}^{2}$ and obesity $\geq 30 \mathrm{~kg} / \mathrm{m}^{2}$ ).

\subsection{Measurement of Whole Blood Selenium}

Whole blood selenium samples were obtained at the beginning of the rehabilitation stay at the Lympho-Opt clinic, using tubes for trace elements/metal analytic. Blood samples were sent to a certified laboratory (biosyn Arzneimittel GmbH, Fellbach, Germany). Selenium levels were measured by microwave digestion and flameless atomic absorption spectrometry, according to the method of Winnefeld et al. [33] Selenium deficiency was assessed using the reference range defined by German authorities [34]. Selenium values in whole blood $<100 \mu \mathrm{g} / \mathrm{L}$ and $<80 \mu \mathrm{g} / \mathrm{L}$ in serum are defined as deficient.

\subsection{Statistical Analysis}

All data were stored and analyzed using GraphPad 8.3. All continuous data are presented as means \pm standard deviation (SD), and the differences were assessed by one-way analysis of variance (normal distribution) or Kruskal-Wallis $\mathrm{H}$ test (non-normal distribution). All categorical data are presented as percentages; the differences were assessed by Pearson chi-square test. Differences between whole blood selenium concentrations in continuous variables were analyzed by Student's t test (normal distribution) and Mann-Whitney test (non-normal distribution) for independent samples. One-way ANOVA was used to compare whole blood selenium concentrations in three or more groups ( $p$ trend). Needed sample size was calculated using $G \times$ Power 3.1.9.7. To calculate the difference between two independent means (two groups), $\alpha=0.05$ and power $=0.80$ was used. Effect size was calculated using Hedges' $\mathrm{g}$, as the sample size of each group was not the same. All $p$ values were 2-sided statistical tests and were considered statistically significant if $<0.05$.

\section{Results}

\subsection{Patients Characteristics}

The study included two time periods from 2012 to $2016(n=236)$ and from 2018 to $2019(n=555)$. Three hundred and forty-seven of 791 patients were diagnosed with a secondary lymphedema (Table 1). In 146 of 347 patients, secondary lymphedema was a sequelae of cancer treatment. Most participants were women $(n=676,85.5 \%)$. Lymphedema was the most common diagnosis in the male patients (106 of 115). There were not any age- or sex-dependent effects on whole blood selenium concentration (data not shown). The study population was stratified for body mass index (BMI) into three groups: $<30$ (normal weight and overweight) $\geq 30<40$ (obese), and $\geq 40$ (morbidly obese). Most lymphedema patients had a BMI < $30(54.8 \% ; 234 / 427))$. In contrast, patients with lipedema and lipo-lymphedema 
were mostly obese $(74.8 \%$, respectively $75.6 \%)$. Baseline characteristics of the study population, stratified for BMI, are presented in Table S1.

Table 1. Descriptive characteristics of patients.

\begin{tabular}{lc}
\hline Characteristic & $\boldsymbol{n = ( \% )}$ \\
\hline Sample, $n$ & 791 \\
Primary lymphedema & 78 \\
\hline Secondary lymphedema, total & 347 \\
$\quad$ Non-cancer & 201 \\
$\quad$ Cancer & 146 \\
\hline Lipedema & 198 \\
Lipo-lymphedema & 168 \\
Selenium status ${ }^{+}, \mu \mathrm{g} / \mathrm{L}$, mean $(\mathrm{SD})$ & $100.6 \pm 17.4$ \\
Selenium deficiency $^{*}$ & $376(47.5)$ \\
\hline * Unless otherwise specified; ${ }^{+}$Selenium concentration in whole blood.
\end{tabular}

\subsection{Selenium Deficiency in the Overall Study Population}

The mean selenium concentration in whole blood was $100.6 \pm 17.4 \mu \mathrm{g} / \mathrm{L}$ (Table 1). Selenium deficiency affected nearly half of the study population (47.5\%), with significant differences in prevalence between lipedema, primary lymphedema, secondary lymphedema and lipo-lymphedema $(41.9 \%<$ $43.6 \%<49.0 \%<53.0 \% ; p=0.0002)$.

In addition, there was a significant difference between selenium levels as a function of BMI. The mean selenium concentration in whole blood was significantly lower in obese and morbidly obese patients compared to those with BMI $<30(p<0.0001)$ (Table S1). The risk of selenium deficiency was 1.7-fold higher in patients with $\mathrm{BMI} \geq 30$ (OR 1.73; 95\% CI 1.30 to 2.30).

\subsection{Selenium Deficiency in Lymphedema}

Whole blood selenium levels did not significantly differ between patients with primary and secondary lymphedema ( $p=0.1827$ ) (Table 2 ). Whole blood selenium concentration by lymphedema stage was analyzed combined for primary and secondary lymphedema. Selenium levels decreased with increasing lymphedema stage ( $p$ trend $=0.0008$; Figure 1 ). As the number of lymphedema stage I was very small $(n=7)$, the risk for selenium deficiency was compared between lymphedema stage II and III. Patients with lymphedema stage III had a 2.2-fold higher risk for selenium deficiency. (OR $2.19 ; 95 \%$ CI 1.40 to $3.39 ; p=0.0007$ ).

Table 2. Selenium concentration in lymphedema.

\begin{tabular}{ccc}
\hline \multirow{2}{*}{ Characteristic } & \multicolumn{2}{c}{ Selenium Concentration in Whole Blood ${ }^{*}, \mu \mathrm{g} / \mathrm{L}$, Mean (SD) } \\
\cline { 2 - 3 } & Primary Lymphedema & Secondary Lymphedema \\
\hline Sample, $n$ & 78 & 347 \\
All & $104.0 \pm 20.9$ & $100.5 \pm 20.3$ \\
Selenium deficiency, $n(\%)$ & $34(43.6)$ & $170(49.0)$ \\
BMI $<30$ & $108.8 \pm 22.2$ & $99.4 \pm 19.5$ \\
BMI $\geq 30<40$ & $97.2 \pm 18.2$ & $96.0 \pm 19.9$ \\
BMI $\geq 40$ & $99.9 \pm 15.4$ & 0.0041 \\
$p$ trend $^{+}$ & 0.0646 & \\
\hline
\end{tabular}

* Unless otherwise specified; ${ }^{+} p$ trend values were calculated using one-way ANOVA for. $p<0.05$ are printed in bold letters. 


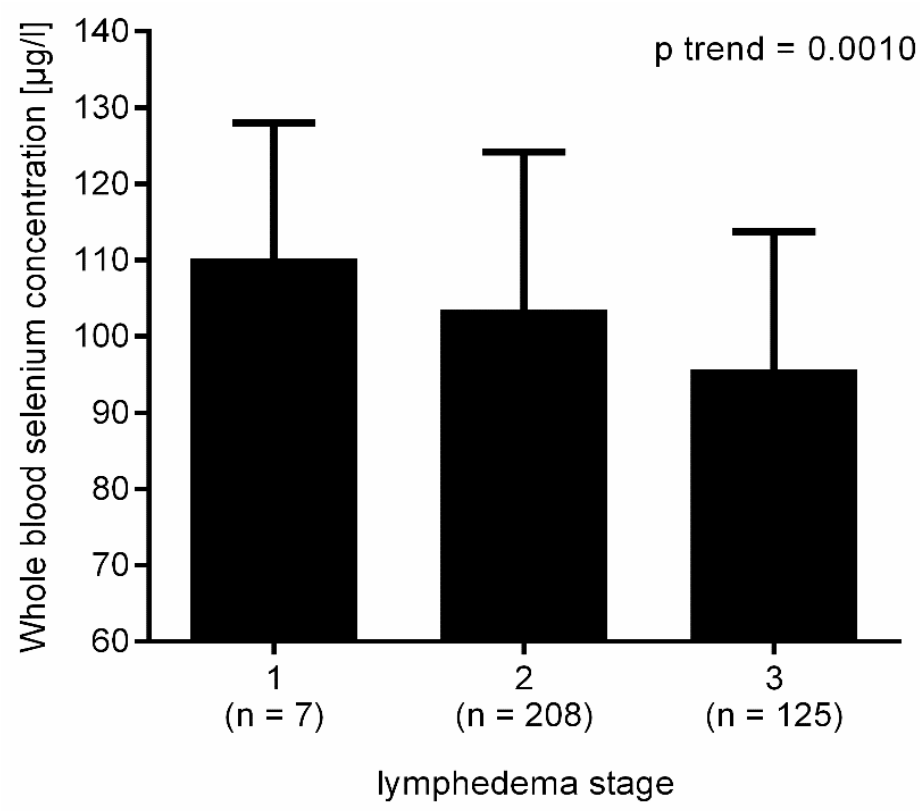

Figure 1. Decreasing selenium values with increasing lymphedema stage.

There was a significant difference in selenium levels between lymphedema patients whose lymphedema was sequelae of cancer treatment and non-cancer lymphedema patients $(p<0.0001$; Figure 2). Interestingly, the difference in whole blood selenium concentration in cancer and non-cancer patients with lymphedema was only significant in the group with a BMI <30 (106.2 \pm 20.0 vs. $98.6 \pm 17.7$; $p=0.0113$ ) (Table S2). The comparison of these two groups for selenium deficiency reflected this result (BMI < 30 cancer vs. non-cancer OR 1.96; 95\% CI 1.07 to 3.63; $p=0.0266 ; \mathrm{BMI} \geq 30$ cancer vs. non-cancer OR 2.08; 95\% CI 0.96 to $4.74 ; p=0.0750)$.

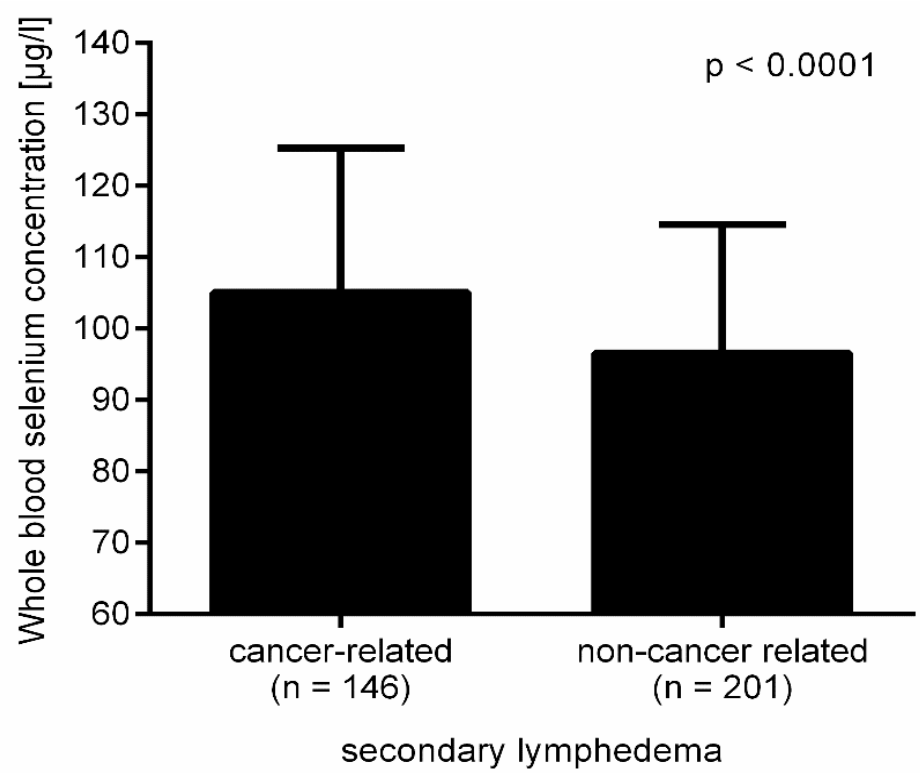

Figure 2. Lower selenium levels in non-cancer related secondary lymphedema.

Whole blood selenium concentration was inversely correlated with BMI independent of the disease (Table S1). BMI distribution differed between cancer patients and non-cancer patients with lymphedema (BMI < 30: 80.1\% vs. 35.8\%; $p<0.0266$ ). 


\subsection{Selenium Deficiency in Lipedema and Lipo-Lymphedema}

Whole blood selenium concentration was significantly different between lipedema and lipo-lymphedema ( $p=0.0127$ ) (Table 3$)$. In addition, there was a significant difference between the prevalence of selenium deficiency (lipedema 41.9\%, respectively, lipo-lymphedema 53.0\%; $p=0.0347$ ). There was no difference between selenium levels, respectively selenium deficiency prevalence in lipedema and lipo-lymphedema patients with a BMI $<30$. However, the selenium status was significantly lower in lipo-lymphedema with $\mathrm{BMI} \geq 30$ ( $p=0.0264$; Table S2). In contrast to lymphedema, there was no significant difference in selenium levels depending on BMI in lipedema and lipo-lymphedema ( $p$ trend $=0.9888$, respectively $p$ trend $=0.0642$ ).

Table 3. Selenium concentration in whole blood in lipedema and lipo-lymphedema.

\begin{tabular}{cccc}
\hline \multirow{2}{*}{ Characteristic } & \multicolumn{3}{c}{ Selenium Concentration in Whole Blood ${ }^{*}, \mu \mathrm{g} / \mathrm{L}$, Mean (SD) } \\
\cline { 2 - 4 } & Lipedema & Lipo-Lymphedema & $p$ Value $^{+}$ \\
\hline Sample, $n$ & 198 & 168 & \\
All & $101.7 \pm 12.3$ & $98.4 \pm 15.6$ & 0.0127 \\
Selenium deficiency, $n(\%)$ & $83(41.9)$ & $89(53.0)$ & 0.0347 \\
BMI $<30$ & $101.7 \pm 14.2$ & $103.3 \pm 13.3$ & 0.7343 \\
BMI $\geq 30<40$ & $101.8 \pm 11.1$ & $97.7 \pm 18.9$ & 0.0692 \\
BMI $\geq 40$ & $101.5 \pm 14.0$ & $96.4 \pm 14.4$ & 0.0254 \\
\hline
\end{tabular}

* Unless otherwise specified; ${ }^{\dagger} p$ values were calculated using $\chi^{2}$ test for categorical variables and Student's $t$ test or Mann-Whitney test. $p<0.05$ are in bold letters.

\subsection{Obesity Increases the Risk for Selenium Deficiency in Lymphedema}

Obesity increased the risk of selenium deficiency in the study population (BMI < $30 \mathrm{vs.} \mathrm{BMI} \geq 30$ : $39.5 \%$ vs. $53.1 \% ; p=0.0002$ ) (Figure 3 ). The different diseases showed a more detailed picture. Selenium concentration in whole blood was significantly decreased in obese patients with lymphedema or lipo-lymphedema, but not with lipedema (Table S2; Figure 4). When comparing obese patients with selenium deficiency to patients with a BMI <30, only obese lymphedema patients displayed a significantly increased risk (OR 2.19; 95\% CI 1.49 to 3.21; $p<0.0001$ ) (Table 4).

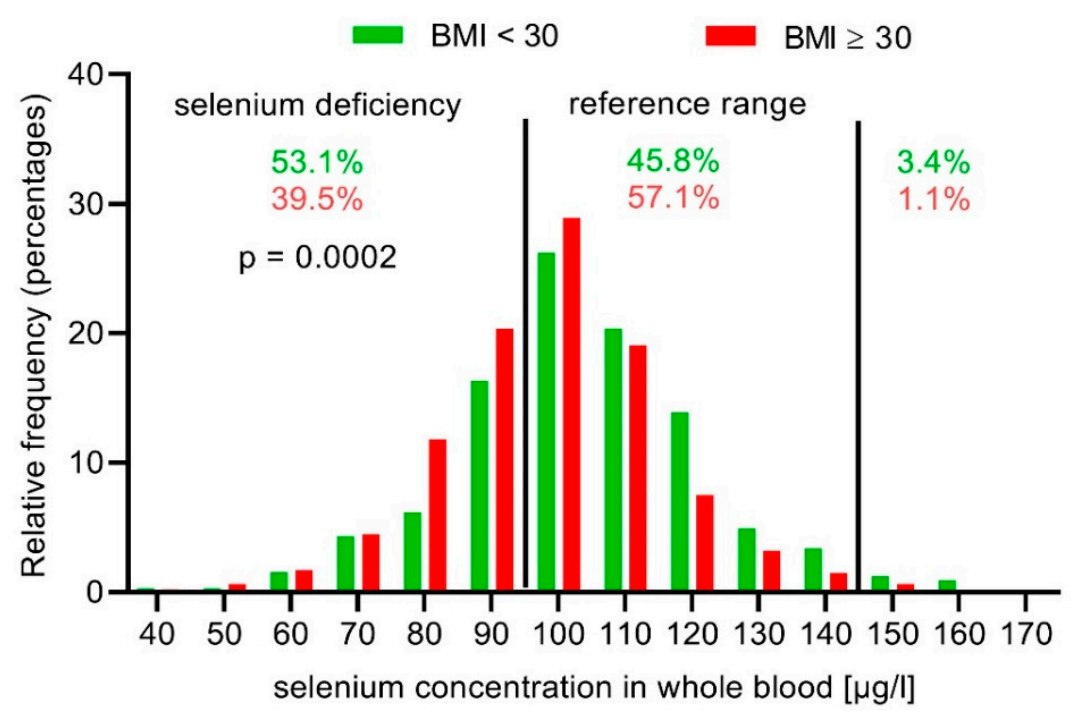

Figure 3. Selenium concentration in whole blood in obese lymphedema, Lipo-lymphedema, and lipedema patients (BMI $\geq 30)$, compared to normal and overweight patients (BMI < 30). 


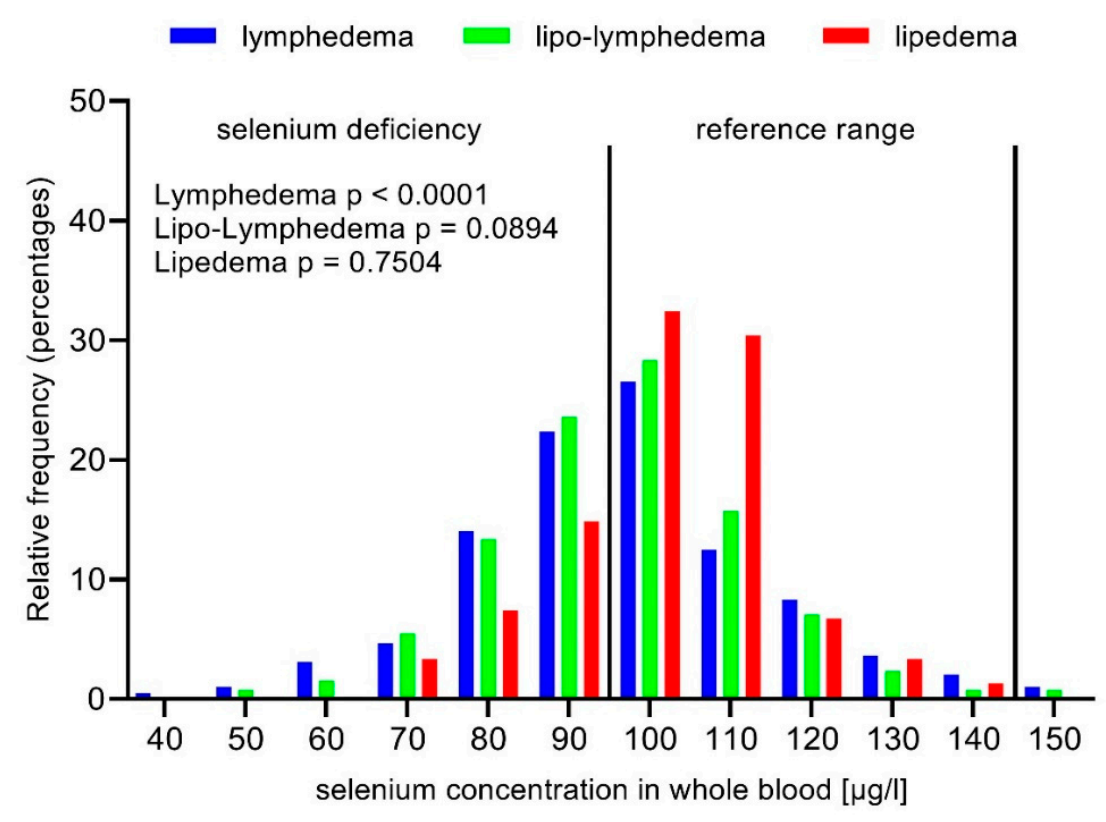

Figure 4. Selenium concentration in whole blood in obese lymphedema, lipo-lymphedema, and lipedema patients (BMI $\geq 30)$.

Table 4. Odds ratio for selenium deficiency in patients with lymphedema, lipo-lymphedema, and lipedema.

\begin{tabular}{|c|c|c|}
\hline & Odds Ratio (95\% CI) & $p$ Value $^{\dagger}$ \\
\hline \multicolumn{3}{|l|}{ Total } \\
\hline $\mathrm{BMI}<30$ & Ref. & Ref. \\
\hline $\mathrm{BMI} \geq 30$ & 1.73 (1.30 to 2.30$)$ & 0.0002 \\
\hline $\mathrm{BMI} \geq 40$ & $1.76(1.27$ to 2.43$)$ & 0.0006 \\
\hline \multicolumn{3}{|c|}{ Lymphedema } \\
\hline $\mathrm{BMI}<30$ & Ref. & Ref. \\
\hline $\mathrm{BMI} \geq 30$ & $2.19(1.49$ to 3.21$)$ & $<0.0001$ \\
\hline $\mathrm{BMI} \geq 40$ & 2.37 (1.49 to 3.74$)$ & 0.0002 \\
\hline \multicolumn{3}{|c|}{ Lipo-Lymphedema } \\
\hline $\mathrm{BMI}<30$ & Ref. & Ref. \\
\hline $\mathrm{BMI} \geq 30$ & $1.85(0.90$ to 3.71$)$ & 0.0894 \\
\hline $\mathrm{BMI} \geq 40$ & $1.88(0.91$ to 4.11$)$ & 0.0995 \\
\hline \multicolumn{3}{|l|}{ Lipedema } \\
\hline $\mathrm{BMI}<30$ & Ref. & Ref. \\
\hline $\mathrm{BMI} \geq 30$ & $0.95(0.46$ to 1.93$)$ & 0.8811 \\
\hline $\mathrm{BMI} \geq 40$ & $1.11(0.58$ to 2.11$)$ & 0.7504 \\
\hline
\end{tabular}

\section{Discussion}

\subsection{Selenium Deficiency in the Total Study Population}

This study aimed to determine the prevalence of selenium deficiency in patients with lymphedema, lipedema, or lipo-lymphedema and a possible influence of obesity as an associated medical condition. The selenium levels in this trial were comparable to whole blood selenium values determined by Muecke et al. in German patients treated in a family doctor practice [35]. Patients without a tumor showed a mean value of $98.9 \pm 19.3 \mu \mathrm{g} / \mathrm{L}$ selenium in whole blood. These data are comparable with the values in this study (overall mean selenium concentration $100.6 \pm 17.4$ ). The results of Muecke et al. and our results show that the mean selenium levels are slightly below or above the German reference 
range of whole blood selenium $(100-140 \mu \mathrm{g} / \mathrm{L})$. It is also apparent that selenium levels vary widely, with whole blood selenium concentrations as low as $43.3 \mu \mathrm{g} / \mathrm{L}$.

Overall, our results showed that selenium deficiency is commonly associated with these medical conditions in a country with low selenium intake. Obesity was an additional risk factor for selenium deficiency in lymphedema.

\subsection{Selenium Deficiency in Lymphedema}

Lymphedemas are divided into primary and secondary (acquired) lymphedema. Primary lymphedema is the result of genetic defects that alter the development of the lymphatic vasculature and typically manifests during infancy, childhood, or adolescence. Less common, primary lymphedema appears after age 35 [36]. Secondary lymphedema is typically caused by surgery, radiation therapy, infection, or trauma. In recent years, another reason is increasingly gaining clinical importance: obesity-related lymphatic impairment [7].

Selenium status was compared in primary and secondary lymphedema. There was no significant difference in selenium levels or selenium deficiency prevalence in the study cohort. Only in secondary lymphedema did selenium levels decrease with increasing BMI, while selenium levels in primary lymphedema were strongly reduced at BMI $\geq 30$. There was no further decline in patients with BMI $\geq 40$. This probably reflects the different etiologies of primary and secondary lymphedema. Obesity seems to be the main risk factor for selenium deficiency in secondary lymphedema. However, obesity can also be a cause of secondary lymphedema. A reduced selenium status is often associated with increased oxidative stress in several diseases and in obesity. The gradual decline in secondary lymphedema could reflect this increasing oxidative stress $[22,37,38]$. On the other hand, the relationship between obesity and the lymphatic system is bidirectional, e.g., defects in the lymphatic function also contribute to the development of obesity [36].

Selenium levels decreased and the risk for selenium deficiency increased with increasing lymphedema stage, possibly due to increased oxidative stress. Progression in lymphedema manifests as fibrosis, which is also closely connected to oxidative stress [1,39]. Siems et al. showed that oxidative stress is increased in lymphedema, although there are no data regarding oxidative stress as a function of lymphedema stage [22].

Non-cancer patients with secondary lymphedema displayed significantly lower selenium levels and a higher risk for selenium deficiency compared to the study patients, in whom lymphedema was sequelae of cancer treatment. This result was unexpected, as cancer patients are at risk of selenium deficiency [40-46]. Therefore, lower selenium levels would be expected in patients with cancer-related lymphedema.

One explanation could be the much higher percentage of obese patients with non-cancer-related lymphedema compared to patients with cancer-related lymphedema. Yet, selenium levels were only non-significantly lower in both obese groups. The significant difference in selenium status was observed in normal weight and overweight patients. If obesity was excluded, one would expect lower selenium levels in cancer patients, not in non-cancer patients, as cancer is also associated with oxidative stress [39]. Siems et al. showed that oxidative stress was increased in chronic lymphedema, but was comparably lower in healthy controls and patients after cancer treatment without lymphedema [22]. Therefore, additional oxidative stress due to cancer or cancer treatment does not seem to increase the risk for selenium deficiency in lymphedema patients. At present, there is no explanation for the increased selenium deficiency risk in non-cancer patients compared to cancer patients.

In summary, selenium deficiency appears to be common in German lymphedema patients. There are some trials that investigated the effect of the inorganic selenium form, sodium selenite, in cancer related lymphedema [17,18,47-49]. In these trials, the combination of high-dosed sodium selenite and standard treatment significantly improved lymphedema compared to standard treatment alone. Those trials did not investigate whether the positive effect was dependent on selenium status. Han et al. treated selenium-replete lymphedema patients only and showed a positive effect of sodium 
selenite [50]. Additionally, sodium selenite was used in many intensive care trials to correct selenium deficiency [51-55].

The effect of selenium deficiency on lymphedema development and progression has not been investigated to date. Avraham et al. showed that Th2 differentiation is essential for the development of lymphatic dysfunction and that inhibiting Th2 cell differentiation with IL-4 and IL-13 monoclonal antibodies improved lymphatic function and decreased fibrosis [56]. Additionally, Th2 helper cells are required for the development of lymphedema and Th2 cytokines; IL-4, and IL-13 are anti-lymphangiogenic, adding to the pathophysiology of lymphedema $[1,57]$. Selenium deficiency favors Th2 differentiation [58]. Therefore, selenium deficiency might increase the potential for lymphedema as an additional risk factor. TGF- $\beta$ is significantly increased in lymphedema and plays an essential role in the development of fibrosis, a hallmark of lymphedema progression [1]. Selenium deficiency causes thyroid fibrosis, which is involved in the pathogenesis of myxoedematous cretinism [59]. TGF- $\beta$ plays a key role in this process. Oglio et al. showed that TGF- $\beta$ disrupted the redox balance in thyroid cells and increased reactive oxygen species [60]. Selenium might partially reverse the effect of TGF- $\beta$. Thus, selenium deficiency appears to play a role in lymphedema progression.

\subsection{Obesity Drives Selenium Deficiency}

The relationship between obesity and the lymphatic system is bidirectional, e.g., defects in lymphatic function contribute to the development of obesity [36]. Conversely, obesity can result in lymphatic impairment [7]. Additionally, obesity is a major risk factor for the development of breast cancer-related upper extremity lymphedema [42].

Obesity was prevalent in the study population, especially in lipedema and lipo-lymphedema patients. Selenium levels decreased in obese patients independent of the medical condition. The risk for selenium deficiency increased 1.7-fold in obese patients. This effect on selenium status was observed in primary and secondary lymphedema, as well as in lipo-lymphedema.

This is consistent with the results of several trials. Alasfar et al. showed that selenium levels were significantly decreased in morbidly obese females [12]. Additionally, selenium status was decreased in obese children [61,62]. In French women, obesity was associated with decreased selenium levels [10]. In a systematic review, Hosseini et al. concluded that the lower status of antioxidants, i.e., selenium, appears to be associated with obesity [9].

On the other hand, lipedema selenium levels remained stable independent of BMI. Oxidative stress plays a role in both lymphedema and lipedema $[22,23,63]$. In obesity and lymphedema, there are changes in the immune response $[7,56]$. The overnutrition-like status of adipocytes dictates changes in adipose immune cells' composition and causes chronic low-grade inflammation, similar to that found in chronic lymphedema [49]. So far, there is no evidence for an altered immune response or inflammation in lipedema. Under conditions of selenium deficiency, innate and adaptive immune responses are impaired [64]. Inflammation is associated with decreased selenium levels [15]. Therefore, one factor for the higher risk of selenium deficiency in lymphedema and lipo-lymphedema could be chronic inflammation.

\subsection{Differences in Selenium Status Between Lipedema and Lymphedema}

The pathogenesis of lymphedema is described as a progressive process, consisting of lymphatic leakage and stagnation, chronic inflammation, adipose tissue expansion and fibrosis [1]. In contrast to lymphedema, lipedema is characterized by the bilateral increased circumference of extremities, pain sensations, and bruising [2]. The combination of lipedema and lymphatic impairment is called lipo-lymphedema [6].

Interestingly, the different etiology of lymphedema and lipedema seems to be reflected by the selenium status. In contrast to lymphedema, lipedema did not display decreasing selenium levels with increasing stage (data not shown). Progression in lymphedema is associated with fibrosis, which is closely connected to oxidative stress [1,39]. In lipedema, progression is characterized by increased 
adipose tissue and liposclerosis [6]. Siems et al. detected high baseline levels of both malondialdehyde and protein carbonyls in lipedema, which are indicative of severe pre-existing oxidative stress and likely represent an accelerated lipid peroxidation in lipedematous tissue [23]. There are no published data comparing oxidative stress levels in lymphedema and lipedema. Therefore, it is speculative whether progressing lymphedema accelerates oxidative stress, thereby leading to an increased selenium requirement and by implication reduced selenium levels, while oxidative stress in lipedema is increased but stable.

Neither did selenium status decrease in lipedema with increasing BMI in contrast to lymphedema. Lipo-lymphedema displayed a trend of decreasing selenium levels with increasing BMI, which is consistent with its description as a lipedema with lymphatic changes. One possible explanation could be the definition of obesity. It is long known that lipedema do not react to diets or exercise. Lipedema are often misdiagnosed as obesity. However, lipedema is a disorder of the adipose tissue [65]. Therefore, it could be an explanation that part of the weight gain in lipedema is different from "normal" weight gain. Then, processes such as increased oxidative stress or chronic inflammation behind obesity that seem to be associated with the decrease in selenium levels would play a bigger role in lymphedema, compared to lipedema or lipo-lymphedema.

Obesity had a significant effect on selenium status in lymphedema and lipo-lymphedema, but not in lipedema. Obesity itself showed a significant effect on selenium levels. A comparable number of lipedema and lipo-lymphedema patients in this study were obese. Only obese lymphedema and lipo-lymphedema patients, not obese lipedema patients, displayed a significant decrease in selenium concentration in whole blood compared to normal- and overweight patients. Therefore, there seems to be an additional factor in lymphedema development and/or progression, which results in decreased selenium levels. So far, there is only a case report in which selenium, in combination with Butcher's broom, was used to treat a patient with stage II lipedema and lipo-lymphedema [66]. The combination helped maintain limb volume reduction after complete decongestive therapy.

\subsection{Strengths and Limitations}

The strength of this study is the total number of participants with lymphedema, lipedema, and lipo-lymphedema, as well as reasonable high numbers for the various diseases, respectively their sub-groups. A further strength is the determination of selenium using whole blood, as it is a better indicator for long-term selenium status compared to serum selenium concentrations. Third, all selenium measurements were conducted in the same certified laboratory ensuring that the results were comparable. Fourth, the specialization of the clinic in these diseases and its long-term experience ensured a correct diagnosis and classification.

Limitations: First, the observational design did not allow for causal relationships across variables to be established. Second, the study population was inherently composed of more advanced diseases, given the specialization of the clinic. Third, the data of the study population was collected during two different time periods that differed in length ( 4 years vs. 2 years) and patient numbers ( 245 vs. 552). In the first time period, selenium levels were only measured in selected patients, in whom selenium deficiency was deemed probable. In the second time period, selenium status was measured in most clinic patients. Forth, the selenium levels were comparable to German patients treated in a family doctor practice [35]. However, representative data regarding the selenium status in healthy Germans are not available. Therefore, the question remains; if selenium values in lymphedema patients are significantly lower compared to healthy German people.

\section{Conclusions}

In countries with selenium intake below recommendations, selenium deficiency is common in secondary lymphedema and lipo-lymphedema. The risk for low selenium values increases in lymphedema patients, if they are also obese. A low selenium status could have a negative effect on secondary lymphedema and lipo-lymphedema, as selenium deficiency is associated with an impaired 
immune function. Further research and clinical trials are necessary to gain more insight into whether selenium deficiency is cause or result, especially in secondary lymphedema. Nonetheless, it would be sensible to check the selenium status in lymphedema patients, especially if they are obese, as infection risk is already increased in lymphedema.

Supplementary Materials: The following are available online at http://www.mdpi.com/2072-6643/12/5/1211/s1, Table S1: Descriptive characteristics of patients stratified for BMI. Table S2: Selenium concentration in obese and morbidly obese patients with lymphedema, lipo-lymphedema, and lipedema. Table S3: Obesity in lymphedema, lipo-lymphedema, and lipedema in two time periods.

Author Contributions: Conceptualization and methodology, all authors; formal analysis, C.P.; investigation and resource H.D. and F.-J.S.; writing-original draft preparation, C.P.; writing-review and editing, C.P.; supervision, F.-J.S.; project administration, H.D. All authors have read and agreed to the published version of the manuscript.

Funding: This research received no external funding.

Conflicts of Interest: Christina Pfister and Horst Dawczynski are employed by biosyn Arzneimittel GmbH. Selenium measurements were performed in the laboratory of biosyn Arzneimittel GmbH. Franz-Josef Schingale did not receive any direct financial support or funding.

\section{References}

1. Hespe, G.E.; Nores, G.G.; Huang, J.-J.; Mehrara, B.J. Pathophysiology of lymphedema-Is there a chance for medication treatment? J. Surg. Oncol. 2017, 115, 96-98. [CrossRef] [PubMed]

2. Wollina, U. Lipedema-An update. Dermatol. Ther. 2019, 32, e12805. [CrossRef] [PubMed]

3. Brauer, W.J.; Weissleder, H. Methodik und Ergebnisse der Funktionslymphszintigraphie: Erfahrungen bei 924 Patienten. Phlebologie 2002, 31, 118-125. [CrossRef]

4. Birkballe, S.; Jensen, M.R.; Noerregaard, S.; Gottrup, F.; Karlsmark, T. Can tissue dielectric constant measurement aid in differentiating lymphoedema from lipoedema in women with swollen legs? Br. J. Dermatol. 2014, 170, 96-102. [CrossRef]

5. Peprah, K.; MacDougall, D. Liposuction for the Treatment of Lipedema: A Review of Clinical Effectiveness and Guidelines; CADTH Rapid Response Reports; Canadian Agency for Drugs and Technologies in Health: Ottawa, ON, USA, 2019.

6. Forner-Cordero, I.; Szolnoky, G.; Forner-Cordero, A.; Kemény, L. Lipedema: An overview of its clinical manifestations, diagnosis and treatment of the disproportional fatty deposition syndrome-Systematic review. Clin. Obes. 2012, 2, 86-95. [CrossRef]

7. Cucchi, F.; Rossmeislova, L.; Simonsen, L.; Jensen, M.R.; Bülow, J. A vicious circle in chronic lymphoedema pathophysiology? An adipocentric view. Obes. Rev. 2017, 18, 1159-1169. [CrossRef]

8. Herpertz, U. Der Mißbrauch des Lipödems. LymphForsch 2003, 7, 90-93.

9. Hosseini, B.; Saedisomeolia, A.; Allman-Farinelli, M. Association Between Antioxidant Intake/Status and Obesity: A Systematic Review of Observational Studies. Biol. Trace Elem. Res. 2017, 175, 287-297. [CrossRef]

10. Arnaud, J.; Bertrais, S.; Roussel, A.M.; Arnault, N.; Ruffieux, D.; Favier, A.; Berthelin, S.; Estaquio, C.; Galan, P.; Czernichow, S.; et al. Serum selenium determinants in French adults: The SU.VI.M.AX study. Br. J. Nutr. 2006, 95, 313-320. [CrossRef]

11. Kimmons, J.E.; Blanck, H.M.; Tohill, B.C.; Zhang, J.; Khan, L.K. Associations between body mass index and the prevalence of low micronutrient levels among US adults. Medscape Gen. Med. 2006, 8, 59.

12. Alasfar, F.; Ben-Nakhi, M.; Khoursheed, M.; Kehinde, E.O.; Alsaleh, M. Selenium is significantly depleted among morbidly obese female patients seeking bariatric surgery. Obes. Surg. 2011, 21, 1710-1713. [CrossRef] [PubMed]

13. Vincent, H.K.; Powers, S.K.; Dirks, A.J.; Scarpace, P.J. Mechanism for obesity-induced increase in myocardial lipid peroxidation. Int. J. Obes. 2001, 25, 378-388. [CrossRef] [PubMed]

14. Vincent, H.K.; Taylor, A.G. Biomarkers and potential mechanisms of obesity-induced oxidant stress in humans. Int. J. Obes. 2005, 30, 400-418. [CrossRef] [PubMed]

15. Huang, Z.; Rose, A.H.; Hoffmann, P.R. The role of selenium in inflammation and immunity: From molecular mechanisms to therapeutic opportunities. Antioxid. Redox Signal. 2012, 16, 705-743. [CrossRef]

16. Vaillant, L.; Gironet, N. Infectious complications of lymphedema. Rev. Med. Interne 2002, 23 (Suppl. 3), 403s-407s. [CrossRef] 
17. Kasseroller, R.G.; Schrauzer, G.N. Treatment of secondary lymphedema of the arm with physical decongestive therapy and sodium selenite: A review. Am. J. Ther. 2000, 7, 273-279. [CrossRef]

18. Micke, O.; Bruns, F.; Mücke, R.; Schäfer, U.; Glatzel, M.; DeVries, A.F.; Schönekaes, K.; Kisters, K.; Büntzel, J. Selenium in the treatment of radiation-associated secondary lymphedema. Int. J. Radiat. Oncol. Biol. Phys. 2003, 56, 40-49. [CrossRef]

19. Bruns, F.; Büntzel, J.; Mücke, R.; Schönekaes, K.; Kisters, K.; Micke, O. Selenium in the treatment of head and neck lymphedema. Med. Princ. Pract. Int. J. Kuwait Univ. Health Sci. Cent. 2004, 13, 185-190. [CrossRef]

20. Büntzel, J.; Riesenbeck, D.; Glatzel, M.; Berndt-Skorka, R.; Riedel, T.; Mücke, R.; Kisters, K.; Schönekaes, K.G.; Schäfer, U.; Bruns, F.; et al. Limited effects of selenium substitution in the prevention of radiation-associated toxicities. results of a randomized study in head and neck cancer patients. Anticancer Res. 2010, 30, 1829-1832.

21. Greene, A.K.; Grant, F.D.; Slavin, S.A. Lower-extremity lymphedema and elevated body-mass index. N. Engl. J. Med. 2012, 366, 2136-2137. [CrossRef]

22. Siems, W.G.; Brenke, R.; Beier, A.; Grune, T. Oxidative stress in chronic lymphoedema. QJM 2002, 95, 803-809. [CrossRef]

23. Siems, W.; Grune, T.; Voss, P.; Brenke, R. Anti-fibrosclerotic effects of shock wave therapy in lipedema and cellulite. Biofactors Oxf. Engl. 2005, 24, 275-282. [CrossRef] [PubMed]

24. Tabibiazar, R.; Cheung, L.; Han, J.; Swanson, J.; Beilhack, A.; An, A.; Dadras, S.S.; Rockson, N.; Joshi, S.; Wagner, R.; et al. Inflammatory manifestations of experimental lymphatic insufficiency. PLoS Med. 2006, 3, e254. [CrossRef] [PubMed]

25. Thomson, C.D.; Robinson, M.F.; Butler, J.A.; Whanger, P.D. Long-term supplementation with selenate and selenomethionine: Selenium and glutathione peroxidase (EC 1.11.1.9) in blood components of New Zealand women. Br. J. Nutr. 1993, 69, 577. [CrossRef] [PubMed]

26. Lei, X.G.; Evenson, J.K.; Thompson, K.M.; Sunde, R.A. Glutathione peroxidase and phospholipid hydroperoxide glutathione peroxidase are differentially regulated in rats by dietary selenium. J. Nutr. 1995, 125, 1438-1446. [CrossRef] [PubMed]

27. Hurst, R.; Armah, C.N.; Dainty, J.R.; Hart, D.J.; Teucher, B.; Goldson, A.J.; Broadley, M.R.; Motley, A.K.; Fairweather-Tait, S.J. Establishing optimal selenium status: Results of a randomized, double-blind, placebo-controlled trial. Am. J. Clin. Nutr. 2010, 91, 923-931. [CrossRef]

28. Hughes, D.J.; Fedirko, V.; Jenab, M.; Schomburg, L.; Méplan, C.; Freisling, H.; Bueno-de-Mesquita, H.B.; Hybsier, S.; Becker, N.-P.; Czuban, M.; et al. Selenium status is associated with colorectal cancer risk in the European prospective investigation of cancer and nutrition cohort: Selenium status is associated with colorectal cancer risk. Int. J. Cancer 2015, 136, 1149-1161. [CrossRef]

29. Muecke, R.; Klotz, T.; Giedl, J.; Buentzel, J.; Kundt, G.; Kisters, K.; Prott, F.-J.; Micke, O. Whole blood selenium levels (WBSL) in patients with prostate cancer (PC), benign prostatic hyperplasia (BPH) and healthy male inhabitants (HMI) and prostatic tissue selenium levels (PTSL) in patients with PC and BPH. Acta Oncol. 2009, 48, 452-456. [CrossRef]

30. Anke, M.; Glei, M.; Dorn, W.; Müller, R.; Vormann, J.; Müller, M.; Jahritz, M.; Seifert, M.; Holzinger, S.; Drobner, S.; et al. Trace Element Intake and Balance in Adults in Central Europe. In Trace Elements in Man and Animals 10; Roussel, A.M., Anderson, R.A., Favrier, A.E., Eds.; Kluwer Academic Publishers: Boston, MA, USA, 2002; pp. 209-214. ISBN 978-0-306-46378-5.

31. Kipp, A.P.; Strohm, D.; Brigelius-Flohé, R.; Schomburg, L.; Bechthold, A.; Leschik-Bonnet, E.; Heseker, H. Revised reference values for selenium intake. J. Trace Elem. Med. Biol. 2015, 32, 195-199. [CrossRef]

32. S2k Guideline-Diagnostics and Therapy of Lymphoedema. 2017. Available online: https://www.awmf.org/fileadmin/user_upload/Leitlinien/058_Ges_D_Lymphologen/058-001le_S2k_ Diagnostics_and_therapy_of_lymphoedema_2019-07.pdf (accessed on 24 April 2020).

33. Winnefeld, K.; Dawczynski, H.; Schirrmeister, W.; Adam, G.; Friedrich, U.; Hein, S. Selenium in serum and whole blood in patients with surgical interventions. Biol. Trace Elem. Res. 1995, 50, 149-155. [CrossRef]

34. Fachinformation Selenase®T Peroral, Biosyn Arzneimittel GmbH, Stand Nov. 2017. Available online: https://www.gelbe-liste.de/produkte/selenase-T-peroral_354493/fachinformation (accessed on 24 April 2020).

35. Muecke, R.; Waldschock, K.; Schomburg, L.; Micke, O.; Buentzel, J.; Kisters, K.; Adamietz, I.A.; Huebner, J. Whole Blood Selenium Levels and Selenium Supplementation in Patients Treated in a Family Doctor Practice in Golßen (State of Brandenburg, Germany): A Laboratory Study. Integr. Cancer Ther. 2018, 17, 1132-1136. [CrossRef] [PubMed] 
36. Escobedo, N.; Oliver, G. The Lymphatic Vasculature: Its Role in Adipose Metabolism and Obesity. Cell Metab. 2017, 26, 598-609. [CrossRef] [PubMed]

37. Marseglia, L.; Manti, S.; D’Angelo, G.; Nicotera, A.; Parisi, E.; Di Rosa, G.; Gitto, E.; Arrigo, T. Oxidative Stress in Obesity: A Critical Component in Human Diseases. Int. J. Mol. Sci. 2014, 16, 378-400. [CrossRef] [PubMed]

38. Sakr, Y.; Reinhart, K.; Bloos, F.; Marx, G.; Russwurm, S.; Bauer, M.; Brunkhorst, F. Time course and relationship between plasma selenium concentrations, systemic inflammatory response, sepsis, and multiorgan failure. Br. J. Anaesth. 2007, 98, 775-784. [CrossRef] [PubMed]

39. Morry, J.; Ngamcherdtrakul, W.; Yantasee, W. Oxidative stress in cancer and fibrosis: Opportunity for therapeutic intervention with antioxidant compounds, enzymes, and nanoparticles. Redox Biol. 2017, 11, 240-253. [CrossRef] [PubMed]

40. Lubinski, J.; Marciniak, W.; Muszynska, M.; Huzarski, T.; Gronwald, J.; Cybulski, C.; Jakubowska, A.; Debniak, T.; Falco, M.; Kladny, J.; et al. Serum selenium levels predict survival after breast cancer. Breast Cancer Res. Treat. 2017. [CrossRef]

41. Meyer, H.A.; Endermann, T.; Stephan, C.; Stoedter, M.; Behrends, T.; Wolff, I.; Jung, K.; Schomburg, L. Selenoprotein P status correlates to cancer-specific mortality in renal cancer patients. PLOS ONE 2012, 7, e46644. [CrossRef]

42. Stevens, J.; Waters, R.; Sieniawska, C.; Kassam, S.; Montoto, S.; Fitzgibbon, J.; Rohatiner, A.; Lister, A.; Joel, S. Serum selenium concentration at diagnosis and outcome in patients with haematological malignancies. Br. J. Haematol. 2011, 154, 448-456. [CrossRef]

43. Franca, C.A.S.; Nogueira, C.R.; Ramalho, A.; Carvalho, A.C.P.; Vieira, S.L.; Penna, A.B.R.C. Serum levels of selenium in patients with breast cancer before and after treatment of external beam radiotherapy. Ann. Oncol. 2011, 22, 1109-1112. [CrossRef]

44. Zeng, Y.C.; Xue, M.; Chi, F.; Xu, Z.G.; Fan, G.L.; Fan, Y.C.; Zheng, M.H.; Zhong, W.Z.; Wang, S.L.; Zhang, Z.Y.; et al. Serum levels of selenium in patients with brain metastases from non-small cell lung cancer before and after radiotherapy. Cancer Radiothér. 2012, 16, 179-182. [CrossRef]

45. Charalabopoulos, K.; Kotsalos, A.; Batistatou, A.; Charalabopoulos, A.; Peschos, D.; Vezyraki, P.; Kalfakakou, V.; Metsios, A.; Charalampopoulos, A.; Macheras, A.; et al. Serum and tissue selenium levels in gastric cancer patients and correlation with CEA. Anticancer Res. 2009, 29, 3465-3467. [PubMed]

46. Kim, I.-W.; Bae, S.-M.; Kim, Y.-W.; Liu, H.-B.; Bae, S.H.; Choi, J.Y.; Yoon, S.K.; Chaturvedi, P.K.; Battogtokh, G.; Ahn, W.S. Serum selenium levels in Korean hepatoma patients. Biol. Trace Elem. Res. 2012, 148, $25-31$. [CrossRef] [PubMed]

47. Bruns, F.; Micke, O.; Bremer, M. Current status of selenium and other treatments for secondary lymphedema. J. Support. Oncol. 2003, 1, 121-130. [PubMed]

48. Zimmermann, T.; Leonhardt, H.; Kersting, S.; Albrecht, S.; Range, U.; Eckelt, U. Reduction of postoperative lymphedema after oral tumor surgery with sodium selenite. Biol. Trace Elem. Res. 2005, 106, 193-203. [CrossRef]

49. Pfister, C.; Dawzcynski, H.; Schingale, F.-J. Sodium selenite and cancer related lymphedema: Biological and pharmacological effects. J. Trace Elem. Med. Biol. 2016, 37, 111-116. [CrossRef]

50. Han, H.W.; Yang, E.J.; Lee, S.-M. Sodium Selenite Alleviates Breast Cancer-Related Lymphedema Independent of Antioxidant Defense System. Nutrients 2019, 11, 1021. [CrossRef]

51. Angstwurm, M.W.A.; Engelmann, L.; Zimmermann, T.; Lehmann, C.; Spes, C.H.; Abel, P.; Strauss, R.; Meier-Hellmann, A.; Insel, R.; Radke, J.; et al. Selenium in Intensive Care (SIC): Results of a prospective randomized, placebo-controlled, multiple-center study in patients with severe systemic inflammatory response syndrome, sepsis, and septic shock. Crit. Care Med. 2007, 35, 118-126. [CrossRef]

52. Andrews, P.J.D.; Avenell, A.; Noble, D.W.; Campbell, M.K.; Croal, B.L.; Simpson, W.G.; Vale, L.D.; Battison, C.G.; Jenkinson, D.J.; Cook, J.A.; et al. Randomised trial of glutamine, selenium, or both, to supplement parenteral nutrition for critically ill patients. BMJ 2011, 342, d1542. [CrossRef]

53. Valenta, J.; Brodska, H.; Drabek, T.; Hendl, J.; Kazda, A. High-dose selenium substitution in sepsis: A prospective randomized clinical trial. Intensive Care Med. 2011, 37, 808-815. [CrossRef] 
54. Bloos, F.; Trips, E.; Nierhaus, A.; Briegel, J.; Heyland, D.K.; Jaschinski, U.; Moerer, O.; Weyland, A.; Marx, G.; Gründling, M.; et al. Effect of Sodium Selenite Administration and Procalcitonin-Guided Therapy on Mortality in Patients with Severe Sepsis or Septic Shock: A Randomized Clinical Trial. JAMA Intern. Med. 2016. [CrossRef]

55. Chelkeba, L.; Ahmadi, A.; Abdollahi, M.; Najafi, A.; Ghadimi, M.; Mosaed, R.; Mojtahedzadeh, M. The effect of high-dose parenteral sodium selenite in critically ill patients following sepsis: A clinical and mechanistic study. Indian J. Crit. Care Med. 2017, 21, 287. [CrossRef] [PubMed]

56. Avraham, T.; Zampell, J.C.; Yan, A.; Elhadad, S.; Weitman, E.S.; Rockson, S.G.; Bromberg, J.; Mehrara, B.J. Th2 differentiation is necessary for soft tissue fibrosis and lymphatic dysfunction resulting from lymphedema. FASEB J. 2013, 27, 1114-1126. [CrossRef] [PubMed]

57. Savetsky, I.L.; Ghanta, S.; Gardenier, J.C.; Torrisi, J.S.; García Nores, G.D.; Hespe, G.E.; Nitti, M.D.; Kataru, R.P.; Mehrara, B.J. Th2 cytokines inhibit lymphangiogenesis. PLoS ONE 2015, 10, e0126908. [CrossRef] [PubMed]

58. Hoffmann, F.W.; Hashimoto, A.C.; Shafer, L.A.; Dow, S.; Berry, M.J.; Hoffmann, P.R. Dietary Selenium Modulates Activation and Differentiation of CD4+ T Cells in Mice through a Mechanism Involving Cellular Free Thiols. J. Nutr. 2010, 140, 1155-1161. [CrossRef]

59. Contempre, B.; Le Moine, O.; Dumont, J.E.; Denef, J.F.; Many, M.C. Selenium deficiency and thyroid fibrosis. A key role for macrophages and transforming growth factor beta (TGF-beta). Mol. Cell. Endocrinol. 1996, 124, 7-15. [CrossRef]

60. Oglio, R.; Thomasz, L.; Salvarredi, L.; Juvenal, G.; Pisarev, M. Comparative effects of transforming growth factor beta isoforms on redox metabolism in thyroid cells. Mol. Cell. Endocrinol. 2018, 470, 168-178. [CrossRef]

61. Azab, S.F.; Saleh, S.H.; Elsaeed, W.F.; Elshafie, M.A.; Sherief, L.M.; Esh, A.M. Serum trace elements in obese Egyptian children: A case-control study. Ital. J. Pediatr. 2014, 40, 20. [CrossRef]

62. Błażewicz, A.; Klatka, M.; Astel, A.; Korona-Glowniak, I.; Dolliver, W.; Szwerc, W.; Kocjan, R. Serum and urinary selenium levels in obese children: A cross-sectional study. J. Trace Elem. Med. Biol. 2015, 29, 116-122. [CrossRef]

63. Chang, T.-C.; Uen, Y.-H.; Chou, C.-H.; Sheu, J.-R.; Chou, D.-S. The role of cyclooxygenase-derived oxidative stress in surgically induced lymphedema in a mouse tail model. Pharm. Biol. 2013, 51, 573-580. [CrossRef]

64. Avery, J.C.; Hoffmann, P.R. Selenium, Selenoproteins, and Immunity. Nutrients 2018, 10, 1203. [CrossRef]

65. Shavit, E.; Wollina, U.; Alavi, A. Lipoedema is not lymphoedema: A review of current literature. Int. Wound J. 2018, 15, 921-928. [CrossRef] [PubMed]

66. Mondry TE, N.S. Bucher's Broom and Selenium Improve Lipedema: A Retrospective Case Study. Altern. Integr. Med. 2013, 2, 119. [CrossRef] 